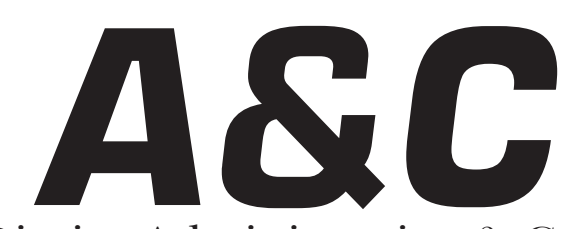

Revista de Direito Administrativo \& Constitucional

Editora Fórum

ISSN 1516-3210

\begin{tabular}{|l|l|l|l|l|l|}
\hline A\&C R. de Dir. Administrativo \& Constitucional & Belo Horizonte & ano 7 & n. 30 & p. 1-254 & out./dez. 2007 \\
\hline
\end{tabular}




\section{A\&C REVISTA DE DIREITO ADMINISTRATIVO \& CONSTITUCIONAL}

IPDA

Instituto Paranaense

de Direito Administrativo

Direção Geral

Romeu Felipe Bacellar Filho

Direção Editorial

Paulo Roberto Ferreira Motta

Direção Executiva

Emerson Gabardo

Conselho de Redação

Edgar Chiuratto Guimarães

Adriana da Costa Ricardo Schier

Célio Heitor Guimarães

\section{Conselho Editorial}

Jorge Luís Salomoni - in memoriam (Argentina)

José Carlos Abraão (Brasil)

José Eduardo Martins Cardoso (Brasil)

José Luís Said (Argentina)

José Mario Serrate Paz (Uruguai)

Juan Pablo Cajarville Peruffo (Uruguai)

Juarez Freitas (Brasil)

Julio Rodolfo Comadira - in memoriam (Argentina)

Luís Enrique Chase Plate (Paraguai)

Lúcia Valle Figueiredo (Brasil)

Manoel de Oliveira Franco Sobrinho -

in memoriam (Brasil)

in memoriam (Brasil)

Marçal Justen Filho (Brasil)

Marcelo Figueiredo (Brasil)
Márcio Cammarosano (Brasil)
Maria Cristina Cesar de Oliveira (Brasil)

Nelson Figueiredo (Brasil)

Odilon Borges Junior (Brasil)

Pascual Caiella (Argentina)

Paulo Eduardo Garrido Modesto (Brasil)

Paulo Henrique Blasi (Brasil)

Paulo Neves de Carvalho - in memoriam

(Brasil)

Paulo Ricardo Schier (Brasil)

Pedro Paulo de Almeida Dutra (Brasil)

Regina Maria Macedo Nery Ferrari (Brasil)

Rogério Gesta Leal (Brasil)

Rolando Pantoja Bauzá (Chile)

Sérgio Ferraz (Brasil)

Valmir Pontes Filho (Brasil)

Yara Stropa (Brasil)

Weida Zancaner (Brasil)

A246 A\&C Revista de Direito Administrativo \& Constitucional. ano 3, n. 11, jan./mar. 2003. Belo Horizonte: Fórum, 2003.

Trimestral

ano 1, n. 1, 1999 até ano 2, n.10, 2002 publicada pela

Editora Juruá em Curitiba

ISSN 1516-3210

1. Direito Administrativo. 2. Direito Constitucional.

I. Fórum.

CDD: 342 CDU: 33.342

(C) Editora Fórum Ltda. 2007

Todos os direitos reservados. É proibida a reprodução total ou parcial, de qualquer forma ou por qualquer meio eletrônico ou mecânico, inclusive através de processos xerográficos, de fotocópias ou de gravação, sem permissão por escrito do possuidor dos direitos de cópias (Lei n 9.610, de 19.02.1998).

Editora Fórum Ltda

Av. Afonso Pena, 2770 - 15\%16 andar - Funcionários

CEP 30130-007 - Belo Horizonte/MG - Brasil

Tel.: 08007043737

Internet: www.editoraforum.com.br

e-mail: editoraforum@editoraforum.com.br
Editor responsável: Luís Cláudio Rodrigues Ferreira Coordenação editorial: Olga M. A. Sousa

Pesquisa jurídica: Fátima Ribeiro - OAB/MG 74868

Revisora: Bárbara Christiane

Projeto gráfico: Luis Alberto Pimenta

Diagramação: Marcelo Belico

Bibliotecária: Alessandra Rodrigues da Silva -

CRB 2459 - 6 ${ }^{a}$ região

Os conceitos e opiniões expressas nos trabalhos assinados são de responsabilidade exclusiva de seus autores.

Impressa no Brasil / Printed in Brazil

Distribuída em todo o Território Nacional 


\title{
Encampação e caducidade - Competên- cia dos consórcios públicos e as agências reguladoras no Brasil
}

\author{
Cristiana Fortini \\ Doutora em Direito Administrativo pela UFMG. Professora do Mestrado da UNIPAC. Professora \\ dos Cursos de Graduação do Centro Universitário Metodista Izabela Hendrix e da PUC Minas. \\ Professora dos Cursos de Pós-graduação do CAD - Centro de Atualização em Direito/Gama Filho \\ e do IEC-PUC Minas. Gerente (Diretora) do contencioso especial da Procuradoria de BH.
}

Palavras-chave: Consórcios públicos. Emenda Constitucional nº 19/1998. Lei no 11.107, de 06 de abril de 2005. Serviços públicos. Administração indireta. Agências reguladoras.

Sumário: 1 Considerações iniciais sobre consórcio - 2 Competências dos consórcios - 3 Possibilidade de encampação e caducidade pelos consórcios - 4 As agências reguladoras - 5 Algumas conclusões - Referências

\section{Considerações iniciais sobre consórcio}

A idéia de que os consórcios públicos refletem meros pactos, formalizados entre entes de igual natureza e estatura, não prevalece após o advento da Emenda Constitucional no 19/98 e, sobretudo, após a edição da Lei $\mathrm{n}^{\mathrm{o}} 11.107 / 05$.

Com efeito, a Emenda Constitucional no 19/98, ao alterar o art. 241, fixou a possibilidade de serem celebrados convênios e consórcios entre os entes federados, explicitando a possibilidade de a União ser partícipe tanto de um quanto do outro. Se a União pode tomar assento em um consórcio, desaparece a distinção traçada por Hely Lopes Meirelles, segundo a qual os consórcios somente poderiam ser ajustados entre pessoas de mesma natureza.

Como já tivemos oportunidade de dizer anteriormente " $\mathrm{O}$ art. 241 veio se somar com outros dispositivos já constantes no texto constitucional que igualmente valorizam a soma de esforços, a reunião de interesses. Destacam-se o art. 23, parágrafo único e o art. $25 \S^{\circ}$. Este último estabelece a possibilidade de os Estados criarem, mediante lei complementar, "regiões metropolitanas, aglomerações urbanas e microrregiões, constituídas

${ }^{1}$ Artigo publicado na Revista Brasileira de Direito Municipal, n. 25.

A\&C R. de Dir. Administrativo \& Constitucional, Belo Horizonte, ano 7, n. 30, p. 141-151, out./dez. 2007 
por agrupamentos de municípios limítrofes, para integrar a organização, o planejamento e a execução de funções públicas de interesse comum”.

A segunda inovação ficou por conta da Lei $\mathrm{n}^{\mathrm{O}} 11.107,{ }^{2}$ de 06 de abril de 2005, que dispõe que os consórcios não traduzem mero pacto, mas formam verdadeira pessoa jurídica, o que os diferenciam de outros modelos de cooperação previstos na Constituição da República, como as regiões metropolitanas, microrregiões e aglomerações urbanas, são entidades. ${ }^{3}$

A Lei $\mathrm{n}^{0} 11.107 / 05$, ao atribuir personalidade jurídica aos consórcios, pretendeu assegurar maior estabilidade aos vínculos de cooperação.

As justificativas constantes do Projeto de Lei $n^{\circ} 3.884 / 04$, que deu origem à Lei $\mathrm{n}^{\circ}$ 11.107/05, eliminam qualquer dúvida acerca da intenção de afastar a precariedade jurídica que poderia comprometer a aproximação dos entes federados, quando unidos por simples pacto.

A partir da lei em questão, os consórcios passam a ser, segundo Celso Antônio Bandeira de Mello, "contratos realizados entre as pessoas de Direito Público de capacidade política, isto é, entre a União, Estados, Distrito Federal e Municípios, em vista da realização de atividades públicas de interesse comum, e dos quais resultará uma pessoa jurídica que os congregará”. ${ }^{4}$

A Lei $n^{0} 11.107 / 05$ foi bem recebida por parte considerável da doutrina. Marçal Justen Filho, por exemplo, entende que a criação de um consórcio entre pessoas administrativas, destituído de personalidade jurídica própria, seria uma inutilidade, porque "corresponderia a uma associação temporária entre pessoas estatais, voltada à execução de um certo projeto, em que a contratação se faria em nome dos consorciados”.

O Professor afirma que o "consórcio público é uma manifestação conjunta e concomitante da atuação de diversos entes federados. Portanto, não é pura solução organizatória interna, por meio da qual um certo ente de federado racionaliza o modo de promover o cumprimento de seus encargos" e que tal figura "propicia o surgimento de sujeitos a quem serão

\footnotetext{
2 Importa destacar que, antes mesmo do advento da Lei n 11.107/05, já existiam consórcios públicos dotados de personalidade jurídica. Como exemplo, cita-se o Consórcio Municipal do Alto do São Francisco em Minas Gerais.

3 É preciso observar que os consórcios já constituídos podem continuar a ostentar a condição de simples pactos. Não fosse assim, o art 41 do Decreto $n^{\circ}$ 6.017/07, que regulamenta a Lei $n^{\circ} 11.107 / 05$, não cuidaria de facultar (e não exigir) a transformação dos consórcios anteriores em consórcios segundo o novo modelo legal. 4 curso de direito administrativo, p. 656.

${ }^{5}$ Parecer disponível em: <www.miguelreale.com.br/parecer.htm>. Acesso em: 21 de set. 2005.
} 
investidas, de modo permanente e contínuo, a execução de tarefas de competência própria dos entes federados".

Nem todos, porém, vislumbram benefícios na caracterização dos consórcios como pessoas jurídicas. Miguel Reale ${ }^{5}$ entende que a atribuição de personalidade jurídica aos consórcios estaria promovendo os mesmos à condição de entes federados, posicionamento que é combatido por Floriano Marques de Azevedo Neto, ao explicar que os consórcios não terão capacidade política e funcionarão como entes de colaboração, cujas competências decorrerão do pacto firmado entre os entes consorciais. ${ }^{6}$

Como também já pudemos nos manifestar "Efetivamente, a partir do momento que se cria uma nova vida, o que envolverá não só a atuação do Executivo, mas também do Legislativo de cada um dos partícipes, na linha de exigências do art. 37, XIX da Constituição da República, reduz-se a precariedade, confere-se, em tese, mais certeza de que o vínculo será mais duradouro e que não será destruído por desentendimentos de menor porte.

Digo isto porque, uma vez a nova pessoa jurídica tendo sido criada por lei (ou seu nascimento pela lei autorizado) de cada ente envolvido no consórcio, a sua extinção exigirá os mesmos procedimentos.

Além disso, a Lei $\mathrm{n}^{\circ} 11.107 / 05$ prevê que a retirada do ente do consórcio seja aprovada pela Assembléia Geral, o que mais uma vez, visa imprimir maior certeza de que a aproximação entre os entes da federação não será resultado de um amor de verão". ${ }^{7}$

De toda sorte, resta evidenciada na lei a necessidade de negociação entre os entes envolvidos. A própria lei faz alusão à palavra contrato em várias passagens, assim como o faz o Decreto $\mathrm{n}^{\mathrm{o}} 6.017 / 07.8$

A Lei $\mathrm{n}^{\mathrm{o}} 11.107 / 05$ admite que o consórcio tanto adote personalidade jurídica de direito público, quanto adote personalidade jurídica de direito privado. ${ }^{9}$ Em verdade, não haverá consórcio submetido integralmente ao direito privado, diante da influência considerável de normas publicistas

\footnotetext{
${ }^{6}$ Parecer disponível em: <https:// www.presidencia.gov.br/sri/consorcios/pareceres.htm>. Acesso em: 20 set. 2005.

${ }^{7}$ Artigo publicado na Revista Brasileira de Direito Municipal, n. 25.

${ }^{8}$ Vide, por exemplo, o art. $6^{\circ}$ do Decreto e os artigos $3^{\circ}$, caput, 5, caput e 12 da Lei $n^{\circ} 11.107 / 05$.

${ }^{9}$ No artigo que publicamos anteriormente, pudemos discutir sobre a adoção do regime de direito privado para os consórcios. Deixamos de estabelecer nova discussão, tendo em vista o tema deste artigo.

${ }^{10}$ Art $6^{\circ}, \S 1^{\circ}$

${ }^{11}$ A doutrina brasileira não é uníssona quanto ao conceito de serviços públicos. As divergências são profundas,
}

A\&C R. de Dir. Administrativo \& Constitucional, Belo Horizonte, ano 7, n. 30, p. 141-151, out./dez. 2007 
relacionadas a concurso público, licitações, prestação de contas, consoante dispõe o art. $6^{\circ}, \S 2^{\circ}$ da Lei $n^{\circ} 11.107 / 05$.

Concordamos com a professora Maria Sylvia Zanella Di Pietro quando ela argumenta que, em ambos os casos, o consórcio passará a compor a Administração Indireta, apesar de a lei assim fixar apenas no que concerne aos consórcios de direito público. ${ }^{10}$

\section{Competências dos consórcios}

O art 241 da CR faz alusão à gestão associada de serviços públicos. No artigo que elaboramos, questionamos: "A primeira pergunta é: a menção a serviços públicos deve ser interpretada de forma restritiva ou extensiva? Vale dizer: os serviços públicos ali referidos são os serviços públicos em sentido limitado, afastando-se, pois, a possibilidade de consórcios que atuem no exercício da atividade ordenadora, ou deve se entender que a expressão fora utilizada de forma mais ampla, contemplando, então, não apenas serviços públicos no aspecto mais limitado, mas ainda outras atividades administrativas. ${ }^{11}$ Não encontramos razão para que se implemente uma interpretação restritiva do dispositivo constitucional.

A criação de uma entidade comum, que possa exercer a atividade ordenadora, naquilo que for de interesse comum, poderá render melhores frutos, uma vez que a soma de material humano e recursos públicos e a uniformização de procedimentos tende a resultar em maior eficiência, ou seja, em alcance de bons resultados, com menor esforço. ${ }^{12}$ Atente-se, porém, que a atividade ordenadora a que fazemos referência é aquela realizada nos meandros da Administração Pública. Não se delegará, por

visto que Celso Antônio Bandeira de Mello emprega o termo apenas quando as comodidades e utilidades são fruíveis diretamente pelos administrados. Diz o autor: "Serviço público é toda atividade de oferecimento de utilidade ou comodidade material destinada á satisfação da coletividade em geral, mas fruível singularmente pelos administrados, que o Estado assume como pertinente a seus deveres e prestar por si mesmo ou por quem Ihe faça as vezes, sob um regime de Direito Público- portanto, consagrador de prerrogativas de supremacia e de restrições especiais- instituído em favor dos interesse definidos como públicos no sistema normativo" (Curso de direito administrativo, p. 634). Vê-se que seu conceito é bem restritivo, nele não se encaixando outros serviços cuja fruição seja generalizada.

${ }^{12}$ A Lei n 11.107/05 modificou a Lei nº 8666/93 em matéria de licitação, de forma a estimular a proliferação de consórcios. $\mathrm{O}$ art. 24 da Lei de Licitações foi alterado, para que seu parágrafo único, passasse a mencionar não apenas as empresas estatais e agências executivas, mas também os consórcios públicos. $\mathrm{O}$ art 17 também foi modificado, afetando a escolha pela modalidade licitatória, quando o licitante for o consórcio. "Art. 17, §8 No caso de consórcios públicos, aplicar-se-á o dobro dos valores mencionados no caput deste artigo quando formado por até 3 (três)entes da Federação, e o triplo, quando formado por maior número".

${ }^{13}$ Veja-se que o STF já decidiu, quando em questão a atuação da ANATEL na Ação Direta de Inconstitucionalidade no 1.668, que a competência da referida agência não pode extrapolar o simples detalhamento da legislação preexistente. Não lhe é dado, então, inovar a ordem jurídica, fixando regras de comportamento que não

A\&C R. de Dir. Administrativo \& Constitucional, Belo Horizonte, ano 7, n. 30, p. 141-151, out./dez. 2007 
obvio, ao consórcio a competência legislativa."13

\section{Possibilidade de encampação e caducidade pelos consórcios}

Se os consórcios se voltam para a "gestão associada de serviços públicos", seria de se lhe reconhecer legitimidade para realizar contratos de concessão e permissão de serviços públicos, nos moldes da Lei n ${ }^{\circ} 8.987$ ou até nos moldes da Lei ${ }^{\circ} 11.079 / 07$.

Segundo o art. $1^{\circ}$, a Lei $\mathrm{n}^{\circ} 11.107 / 05$ estabelece normas gerais para que os entes contratem consórcios públicos "para a realização de objetivos de interesse comum".

Levando-se em conta que a lei em comento deriva do art. 241 da CR, o qual prevê a união em torno da "gestão associada de serviços públicos", não nos parece possa se colocar óbice à escolha pela prestação indireta dos serviços, ou seja, pela prestação por meio da iniciativa privada. ${ }^{14}$

Para eliminar qualquer questionamento, a Lei $\mathrm{n}^{\mathrm{o}} 11.107 / 05$ admite que os consórcios públicos celebrem concessão, permissão ou autorização de serviços públicos, mediante autorização prevista no contrato de consórcio público. ${ }^{15}$ Em verdade, antes mesmo da previsão no contrato de consórcio público, deverá o protocolo de intenções estabelecer tal sorte de competência, já que este é o instrumento que primeiro delineia as tarefas a cargo da entidade consorcial. ${ }^{16}$

Vale dizer, o protocolo de intenções, a ser ratificado como já se disse, precisaria admitir que a pessoa jurídica do consórcio delegasse a prestação do serviço público, ao invés de realizar diretamente tal atividade. Surge, então, a seguinte pergunta: celebrado o contrato de concessão de serviços públicos pelo consórcio, a quem caberia decidir pela encampação ou pela caducidade? ${ }^{17}$

\footnotetext{
estejam já disciplinadas em lei.

${ }^{14} \mathrm{Na}$ esfera das atividades administrativas, o que poderia ser desempenhado por um ente federado, isoladamente, pode ser realizado pelos entes federados, unidos em torno da figura consorcial, desde que tenha lastro legal, em especial no art $2^{\circ} \S 1^{\circ}$ da Lei $n^{\circ} 11.107 / 05$ e possa ser visto com "objetivos de interesse comum".

${ }^{15}$ Art. $4^{\circ} \mathrm{XI}$, " $\mathrm{c}^{\prime \prime}$ combinado com o art $2^{\circ} \S 3^{\circ}$, ambos da Lei $\mathrm{n}^{\circ} 11.107 / 05$.

${ }^{16}$ Nesse sentido, estabelece o Decreto $n^{\circ} 6.017 / 07$, em seu art. 50, XII "c".

17 Nos termos do art 37, da Lei n 8.987/95 encampação é "a retomada do serviço pelo poder concedente durante o prazo da concessão, por motivos de interesse público, mediante lei autorizativa específica e após prévio pagamento da indenização, na forma do artigo anterior". A caducidade, por sua vez, é mencionada no art 38 da mesma lei,como conseqüência da inexecução total ou parcial do contrato pela concessionária.

18 Marcus Juruena Villela Souto argumenta que a independência das agências reguladoras é relativa em face do princípio da jurisdição uma, aduzindo que a submissão dos entes ao Poder Judiciário enfraquece a sua força (Agências Reguladoras. Revista de Direito Administrativo, n. 216, abr./jun. 1999).
} 


\section{As agências reguladoras}

Esta pergunta incomodou e ainda incomoda os estudiosos do Direito Administrativo, quando em pauta está a atuação das agências reguladoras.

Sabe-se que as agências reguladoras foram criadas na tentativa de minimizar a influência política na fiscalização da execução de serviços públicos bem como no controle da prática de atividades econômicas cruciais, garantindo-se, assim, maior transparência e estabilidade às relações travadas nessa seara.

Nesse viés, idealizou-se a criação de uma autarquia vista como especial, porque, entre outras razões, seus dirigentes teriam mandato fixo, insuscetível de interrupção por fundamentos de ordem política. ${ }^{18}$

O mandato somente pode ser interrompido nas hipóteses alinhavadas na Lei Geral $n^{\circ}$ 9986/00, ${ }^{19}$ bem como na lei de cada uma das agências, sendo certo, porém, que as leis criadoras não teriam liberdade absoluta para incrementar as situações ensejadoras da perda do mandato. Atente-se, por exemplo, para o fato de o STF ter considerado inconstitucional lei do Estado do Rio Grande do Sul que havia fixado, como causa capaz de interromper o mandato. ${ }^{20}$

A independência dos dirigentes seria algo tão crucial para a essência e individualidade das agências reguladoras, que sequer o fim do mandato do governante (Presidente da República, por exemplo) teria o condão de influenciar o mandato dos comandantes da autarquia especial. ${ }^{21}$

Tamanha "independência" merece crítica por parte de alguns professores. O eminente Professor Celso Antônio Bandeira de Mello, por exemplo, entende que a garantia dos mandatos não pode se estender "além de

\footnotetext{
${ }^{19} \mathrm{O}$ art. $9^{\circ}$ da Lei n 9986/00 estabelece as hipóteses de perda de mandato. O parágrafo único do art. $9^{\circ}$ admite a criação, pela lei de cada uma das agências, de novas situações que levem à perda do mandato.

${ }^{20}$ Medida cautelar em Ação Direta de Inconstitucionalidade n 1.949 - Rio Grande do Sul. "A investidura a termo — não impugnada e plenamente compatível com a natureza das funções das agências reguladoras —é, porém, incompatível com a demissão ad nutum pelo Poder Executivo: por isso, para conciliá-la com a suspensão cautelar da única forma de demissão prevista na lei — ou seja, a destituição por decisão da Assembléia Legislativa impõe-se explicitar que se suspende a eficácia do art. $8^{\circ}$ dos diplomas estaduais referidos, sem prejuízo das restrições à demissibilidade dos conselheiros da agência sem justo motivo, pelo Governador do Estado, ou da superveniência de diferente legislação válida".

${ }^{21} \mathrm{O}$ art $7^{\circ}$ da Lei n 9.986/00 fixa para a lei de cada agência o dever de dispor sobre a forma da não-coincidência do mandato.

${ }^{22}$ Curso de direito administrativo, p. 160.

${ }^{23}$ A respeito da constitucionalidade da participação do legislativo na decisão pela celebração da concessão já escrevemos no livro Contratos administrativos: franquia, concessão, permissão e PPP. Belo Horizonte: Del Rey, 2007.
} 
um mesmo período governamental", porque isso inibiria "a sobrevinda de diretrizes novas próprias dos que ascendessem nas eleições sucessivas”. ${ }^{22}$

Críticas à parte, o que mais atrai nossa atenção, neste trabalho, é a dúvida sobre a competência para romper os contratos de concessão de serviços públicos, seja por encampação, seja por caducidade, nas hipóteses de existir agência reguladora a fiscalizar.

A leitura isolada da Lei $\mathrm{n}^{\circ}$ 8.987/95 autorizaria concluir que a decisão pelo rompimento prematuro, num caso ou noutro, seria do ente federado (poder concedente) titular do serviço público delegado.

Tal conclusão decorreria dos artigos $38 \S 1^{\circ}$ e 37 da Lei $n^{\circ} 8.987 / 95$, que mencionam a necessidade de Decreto do Chefe do Poder Concedente, para a hipótese de caducidade e lei autorizativa (além, é obvio, da manifestação do executivo nesse sentido) emanada pelo Poder Legislativo envolvido.

A exigência de Lei, no caso da encampação, enquanto o decreto seria o instrumento, no caso de caducidade, se explica à medida que a decisão pela retomada do serviço, por razões de interesse público, sem se atribuir falta à concessionária, há de observar os mesmos passos que foram exigidos para que se decidisse pela concessão. Se a decisão pela concessão é compartilhada entre Legislativo e Executivo, a encampação também deve decorrer do acerto entre os dois Poderes. A caducidade, por outro lado, não reflete decisão de ordem política, mas questão administrativa. Ou seja, a decretação da caducidade não resulta da vontade política, mas, ao contrário, reflete medida fundamental para se garantir a aplicação dos princípios basiladores do serviço público. ${ }^{23}$

Com base em tais dispositivos e usando também o argumento de que decisão pela ruptura cabe ao ente político titular do serviço, poder-se-ia concluir pela incompetência das agências reguladoras adotarem tais medidas. Entendo haver uma dose de razão para esse entendimento. Com efeito, a encampação, rescisão provocada pela falta de interesse público e não por falhas na atuação da empresa, somente pode ser realizada por quem tenha competência para decidir pela forma de prestação do serviço.

\footnotetext{
${ }^{24}$ Agências Reguladoras. Curitiba: Manole, 2003. p. 106.

25 Art. 19, Inciso V.

${ }^{26}$ Agências Reguladoras da Administração. Revista de Direito Administrativo, n. 221, jul./set. 2000.

27 BARROSO. Dez anos da Constituição de 1988 (foi bom para você também?). Revista Trimestral de Direito
}

A\&C R. de Dir. Administrativo \& Constitucional, Belo Horizonte, ano 7, n. 30, p. 141-151, out./dez. 2007 
Quem decidiu pela concessão, em dado momento, pode, posteriormente, alterar seu posicionamento, a partir de dados técnicos ou financeiros que recomendem, por exemplo, que a prestação do serviço público volte a ocorrer de forma direta.

Assim, não nos parece possível admitir que as agências reguladoras sejam dotadas deste tipo de competência (para encampar), sob pena de lhes reconhecer, enfim, prerrogativas relacionadas à elaboração de políticas públicas.

Mas, quanto à caducidade, entendemos de forma diversa. A caducidade reflete um dever de interromper a relação jurídica, que recai sobre a Administração Pública, diante do descompromisso da concessionária frente ao contrato e à lei, demonstrado mediante condutas graves (não se admitirá a aplicação da caducidade, quando tal ato representar ofensa à razoabilidade e à proporcionalidade).

Trata-se, no nosso entender, de conduta imperiosa, quando se detecta que a manutenção do pacto provocará risco de grave lesão ao interesse público. Ora, a agência reguladora foi criada exatamente para que a fiscalização/controle ocorresse sem a presença de fatores políticos.

Paulo Roberto Ferreira Motta discorre sobre o tipo ideal de agência, dotado de autonomia administrativa, política, orçamentária e financeira, embora se apresente cético quanto à sua materialização no Brasil. "Os entes reguladores são instrumentos de publicização da prestação de serviços públicos por particulares. Essa visão de agência tipo ideal que, de resto, encontra eco na doutrina estrangeira, parte, conforme visto, da publicização daquelas, estabelecendo uma série de regras típicas de direito público para o funcionamento regular das agências reguladoras". ${ }^{24}$

Se a agência não puder romper o contrato, quando, após regular processo administrativo, vislumbrar risco ao interesse público, o controle real e efetivo estaria, de novo, devolvido ao ente federado e, portanto, a influência política que se quis afugentar retornaria à cena.

A Lei $\mathrm{n}^{\circ}$ 9.742/97, na esteira desse raciocínio, prevê entre as competências da ANATEL, o dever-poder de "editar atos de outorga e extinção de direito de exploração do serviço no regime público". ${ }^{25}$

Público, p. 39.

A\&C R. de Dir. Administrativo \& Constitucional, Belo Horizonte, ano 7, n. 30, p. 141-151, out./dez. 2007 
Logo, parece-nos possível (mais do que isso, imprescindível) reconhecer às agências reguladoras dever-poder de rescindir, por caducidade, os contratos de concessão de serviços públicos.

O eminente Professor Caio Tácito já asseverou que as funções das agências reguladoras "mantém o adequado equilíbrio entre a política de privatização e a preservação do interesse público, harmonizando a liberdade com a adequação dos fins básicos da manutenção dos interesses da comunidade A privatização transfere o serviço público à gestão privada. O poder público retém, contudo, a supervisão sobre o exercício regular da atividade..." 26

Não admitir às agências reguladoras a decretação de caducidade seria realizar uma interpretação retrospectiva, condenada por Luís Roberto Barroso porque através dela "se procura interpretar o texto novo de maneira a que ele não inove nada, mas, ao revés, fique tão parecido quanto possível com o antigo". ${ }^{27}$

Voltando aos consórcios, cumpre verificar se estes poderiam romper as concessões que tivessem celebrado. Ora, se no caso das agências reguladoras admitimos que estas estabeleçam a caducidade, quando não foram elas as signatárias das concessões, o que dizer dos consórcios que figuraram eles próprios como concedentes?

No caso dos consórcios, entendemos que não apenas a caducidade é possível, como também a encampação.

Isso porque aos consórcios pode se reconhecer a prerrogativa de decidir pela participação da iniciativa privada, em regime de concessão ou permissão.

Ora, se os consórcios podem assumir tal mister e, consequentemente, podem celebrar os pactos com empresas privadas, parece inegável que os mesmos assumem a prerrogativa de rescindir os contratos não apenas na hipótese de detectar-se falha na prestação, mas também quando advierem razões relacionadas ao interesse público que afirmem a conveniência da ruptura.

Os consórcios distam das agências reguladoras, entre outras razões, porque elas são entes de fiscalização e controle (não de execução), enquan-

A\&C R. de Dir. Administrativo \& Constitucional, Belo Horizonte, ano 7, n. 30, p. 141-151, out./dez. 2007 
to os primeiros também assumem o lugar dos entes federados podendo prestar o serviço público ou delegá-lo a terceiros. Por isso, entendemos imperioso tratar as duas figuras de forma distinta.

\section{Algumas conclusões}

a) Os consórcios são entes criados a partir de negociações travadas entre os entes federados, que comporão, no nosso entender, a Administração Indireta ainda que assumam a personalidade jurídica de direito privado (híbrida, em verdade).

b) Os consórcios podem ser criados para prestar serviços públicos diretamente ou mediante concessão/permissão à iniciativa privada, desde que autorizados a tanto.

c) Os consórcios, caso deleguem à iniciativa privada a prestação de serviços públicos, estão aptos a rescindir o contrato após detectar falha na atuação da empresa (observados os princípios da razoabilidade, proporcionalidade e ampla defesa, dentre outros) ou após concluir pela ausência de interesse público na preservação da avença.

d) As agências reguladoras, porém, somente podem decretar a caducidade dos contratos de concessão/permissão, visto que são entidades detentoras de poder de fiscalização. Mas, não exercem a gestão do serviço de forma ampla, o que as impede de rescindir por encampação.

\section{Referências}

BANDEIRA DE MELLO, Celso Antônio Curso de direito administrativo. 20. ed. São Paulo: Malheiros, 2006.

BARROSO, Luís Roberto. Dez anos da Constituição de 1988 (foi bom para você também?). Revista Trimestral de Direito Público, n. 20, p. 39, 1997.

BORGES. Alice Gonzalez. Os consórcios públicos na sua legislação reguladora. Revista Eletrônica de Direito do Estado, Salvador, Instituto de Direito Público da Bahia, n. 6. maio/jul. de 2006. Disponível em: <https: //www.direitodoestado.com.br>. Acesso em: junho 2006.

CARVALHO FILHO, José dos Santos. Manual de direito administrativo. 17. ed. Rio de Janeiro: Lúmen Juris, 2007.

JUSTEN FILHO, Marçal. Parecer. Disponível em: < https:// www.presidencia.gov.br/sri/ consórcios/pareceres.htm>. Acesso em: set. 2005.

A\&C R. de Dir. Administrativo \& Constitucional, Belo Horizonte, ano 7, n. 30, p. 141-151, out./dez. 2007 
MARQUES NETO, Floriano. Parecer. Disponível em: < https:// www.presidencia.gov.br/sri/ consórcios/pareceres.htm>. Acesso em: set. 2005.

MEDAUAR, Odete; OLIVEIRA, Gustavo Justino de. Consórcios Públicos- comentários à Lei 11.107/2005. São Paulo : R. dos Tribunais, 2006

MEIRELLES, Hely Lopes. Direito administrativo brasileiro. São Paulo: Malheiros, 199-.

MOTTA, Paulo Roberto Ferreira. Agências reguladoras Curitiba: Manole, 2003.

PORTO NETO, Benedicto. Parecer. Disponível em: < https:// www.presidencia.gov.br/sri/ consórcios/pareceres.htm>. Acesso em: set. 2005.

TÁCITO, Caio. Agências reguladoras da Administração. Revista de Direito administrativo, n. 221. jul./set. 2000.

SOUTO, Marcus Juruena Villela. Agências reguladoras. Revista de Direito Administrativo, n. 216, abr./jun. 1999.

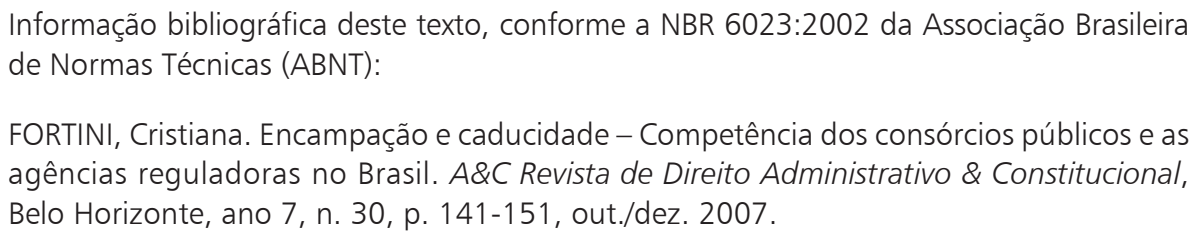

FORTINI, Cristiana. Encampação e caducidade - Competência dos consórcios públicos e as agências reguladoras no Brasil. A\&C Revista de Direito Administrativo \& Constitucional, Belo Horizonte, ano 7, n. 30, p. 141-151, out./dez. 2007.

A\&C R. de Dir. Administrativo \& Constitucional, Belo Horizonte, ano 7, n. 30, p. 141-151, out./dez. 2007 